\title{
Development of Small-Scale Facilities for Initiating Studies into Sea Wave Energy Generation
}

\author{
D G Dorrell ${ }^{1}$, R Halliday ${ }^{1}$, S. McLean ${ }^{2}$, P. Miller $^{1}$ and F. Santamaria Mosquera ${ }^{1}$ \\ ${ }^{1}$ Department of Electronics and Electrical Engineering \\ ${ }^{2}$ Dept of Civil Engineering \\ University of Glasgow, Oakfield Avenue, Glasgow, G12 8LT, UK \\ Tel: +44 141330 2768, email: d.dorrell@elec.gla.ac.uk
}

\begin{abstract}
This paper describes the preliminary work carried out within the Civil and Electronics and Electrical Engineering Departments of The University of Glasgow. Two experimental pieces of equipment are described; the first is a piston-type of device suitable for testing small turbines in an oscillating water column system. The second is the conversion of a water flume into a wave tank for use in tests of small wave generator models and wave prediction systems.
\end{abstract}

\section{Key words}

Wave energy, oscillating water column, wells turbine, flume, wave tank.

\section{Introduction}

Recently there has been new research projects instigated in the Electronics and Electrical Engineering Department of the University of Glasgow [1-4]. These have been aimed at investigating small wave generator models. The first set of results [1] were obtained from a small oscillating water column with a Wells turbine which was tested in a wave tank available in the Marine Engineering Department at Glasgow University (Fig 1). This has the problem that, even though the water column is small, the facility is large (tying up facilities) and steady-state operation is difficult since, even with a good beach, there are reflections, so that the maximum number of waves in any one run is about thirty.

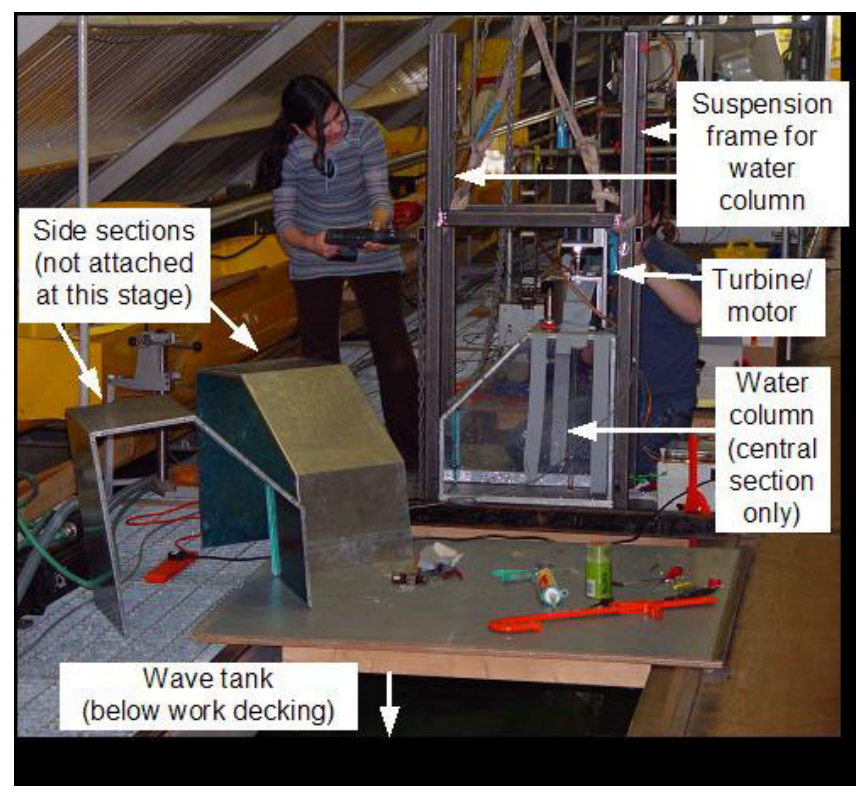

Fig 1 Initial oscillation water column testing in wave tank
It was decided to decouple the turbine from the water column and build a piston to test the turbines separately. Also it was decided to develop a flume, normally used in river flow and tidal studies, into a test bed for small wave generator models and for studies into short-term wave prediction methods. The advantages with the flume arrangement are that it was available locally in the adjoining Department of Civil Engineering and also the cost of developing the wave tank is relatively low and during testing there is no requirement to have technician assistance available - either for technical help or to satisfy health and safety requirements. These facilities, and initial experimental results, are described here.

\section{Turbine test bed}

This was designed to allow the testing of turbines of a diameter of up to about $200 \mathrm{~mm}$. Fig 2 shows the basic dimensions of the test bed developed to test the turbines.

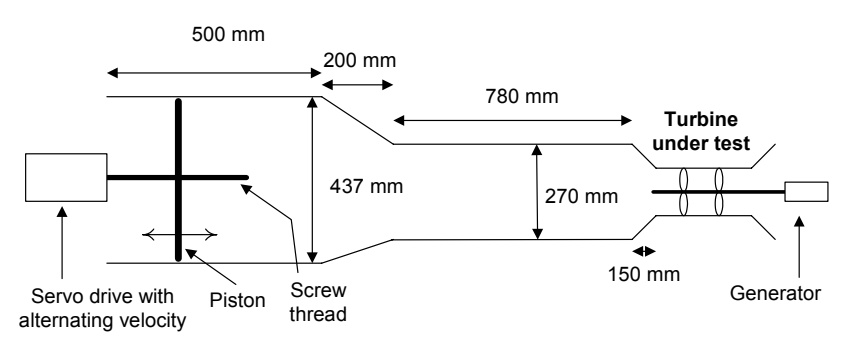

Fig 2 Dimensions of turbine piston test bed

The large piston has a diameter of $437 \mathrm{~mm}$ and a stroke of about $250 \mathrm{~mm}$. The maximum frequency is designed to be about $0.5 \mathrm{~Hz}$ which requires the drive to be low inertia and high torque. Two photographs of the system during the manufacturing and initial testing are shown in Figs 3 and 4.

Fig 3 shows the turbine located on the left-hand side. The performance assessment of the initial Wells turbine designs (both using CFD and by measurement) are given elsewhere [2][4]. It was found that the Wells turbine had a Reynolds number that was far too low for this size. The performance could be improved using swivelling blades and there is also a program to investigate an impulse turbine.

The energy in the wave front in deep water is obtained from the equation 


$$
P=\frac{\sigma g^{2} H^{2}}{32 \pi f}=\frac{981.2 H^{2}}{f} \quad \mathrm{~W} / \mathrm{m}
$$

where $H$ is the wave height, $f$ is the frequency, $\sigma$ is the density of sea water $\left(1025 \mathrm{kgm}^{-3}\right)$ and $g$ is gravity. It can be seen that the power increase with wave height squared but is inversely proportional to the frequency. The Wells turbine under test operated well at a frequency of about $0.55 \mathrm{~Hz}$. If oscillations inside the cylinder are about $250 \mathrm{~mm}$ then the external waves would have a minimum of about $111 \mathrm{~W} / \mathrm{m}$ (though they are likely to be higher than this since the internal water level in a chamber may not oscillate at the same amplitude as the external water height in an actual column. Using the diameter of the cylinder as the width of water front then this would be a resource of $48.5 \mathrm{~W}$. If we aim for a $50 \%$ conversion factor then we wish to obtain about $24 \mathrm{~W}$ maximum out of the turbine. This is still to be achieved in the initial wave-tank tests since the turbine design is still being developed.

It can be seen in Fig 4 that the servo drive is connected by a belt; this was the initial design that utilised a servo drive already available in the laboratory. However this system is still under investigation since the load requirement for this system set-up is quite demanding. This is illustrated below. The thread of the piston screw is $2.5 \mathrm{~mm}$ so that for a 250 $\mathrm{mm}$ oscillation 100 turns are required which is $200 \pi$ radians. Therefore, for a sinusoidally-oscillating system

$$
\theta_{s h}(t)=100 \pi \sin \left(2 \pi f_{W} t\right) \operatorname{rad}
$$

where $\theta_{s h}$ is the shaft angular position and $f_{W}$ is the wave frequency. The piston shaft rotational velocity is

$$
\omega_{s h}=\frac{\mathrm{d} \theta_{s h}(t)}{\mathrm{d} t}=200 \pi^{2} f_{W} \cos \left(2 \pi f_{W} t\right) \mathrm{rad} / \mathrm{sec}
$$

which, in terms of rpm, is

$$
\begin{aligned}
& N_{s h}=\frac{60}{2 \pi} \times 200 \pi^{2} f_{W} \cos \left(2 \pi f_{W} t\right) \\
& N_{s h}=18850 f_{W} \cos \left(2 \pi f_{W} t\right) \quad \mathrm{rpm}
\end{aligned}
$$

At a frequency of $0.6 \mathrm{~Hz}$ (say to give some margin) then the peak speed is $11310 \mathrm{rpm}$. The maximum speed of the drive motor is $4000 \mathrm{rpm}$, hence gearing is required. The correct gearing should be at least 2.83. However the inertia of the system has to be considered. If we consider the solely the motor then the acceleration is

$$
\frac{\mathrm{d} \omega_{m}}{\mathrm{~d} t}=\frac{1}{K_{\text {gear }}} \frac{\mathrm{d} \omega_{s h}}{\mathrm{~d} t}=-\frac{400 \pi^{3} f_{W}^{2}}{K_{\text {gear }}} \sin \left(2 \pi f_{W} t\right) \mathrm{rad} / \mathrm{s}^{2}
$$

which gives a peak acceleration of $1578 \mathrm{rad} / \mathrm{s}^{2}$. Ignoring friction, windage and other load losses, the equation for the torque is approximately

$$
T_{m}=J \frac{\mathrm{d} \omega_{m}}{\mathrm{~d} t} \mathrm{Nm}
$$

The motor inertia is quoted as $0.249 \times 10^{-3} \mathrm{Kg} / \mathrm{m}^{2}$ so that the required torque is $0.39 \mathrm{Nm}$. However, the inertia of the steel shaft and the gearing has to be included. The shaft is $1.2 \mathrm{~m}$ long with a diameter of $20 \mathrm{~mm}$. The mass is then $1.2 \times$ $\pi \mathrm{D}^{2} / 4 \times \rho=2.95 \mathrm{Kg}$ (where $\rho$ is $7833 \mathrm{Kg} / \mathrm{m}^{3}$ ), therefore the inertia $=0.5 \times 2.95 \times 0.01^{2}=0.148 \times 10^{-3} \mathrm{Kg} / \mathrm{m}^{2}$. If the belt wheel of the motor is $22 \mathrm{~mm}$ wide and $200 \mathrm{~mm}$ in diameter then the mass is $5.41 \mathrm{Kg}$ if made from steel giving an inertia of $0.5 \times 5.41 \times 0.1^{2}=27 \times 10^{-3} \mathrm{Kg} / \mathrm{m}^{2}$. The belt wheel of the shaft will then be $71.4 \mathrm{~mm}$ to give the correct ratio so that the weight is $0.69 \mathrm{Kg}$ giving an inertia of $0.44 \times 10^{-3}$ $\mathrm{Kg} / \mathrm{m}^{2}$.

The inertia is multiplied by the square of $K_{\text {gear }}$, i.e., the torque equation is modified to:

$$
\begin{array}{r}
T_{m}=J_{m}+J_{g 1}+K_{\text {gear }}^{2}\left(J_{\text {sh }}+J_{g 2}\right) \frac{\mathrm{d} \omega_{m}}{\mathrm{~d} t} \mathrm{Nm} \\
T_{m}=\left\{0.249+27+2.8^{2}(0.148+0.44)\right\} \times 10^{-3} \times 1578 \\
=\{0.249+27+4.6\} \times 10^{-3} \times 1578=50.2 \mathrm{Nm}
\end{array}
$$

This clearly shows the problem with the system as being the diameter of the motor drive wheel. Its inertia clearly puts the torque beyond the $3.39 \mathrm{Nm}$ rating of the motor. If the diameter is halved then the weight will decrease by 4 and the inertia by $4 \times 4=16$. However the diameter of the shaft wheel will then only be $35.7 \mathrm{~mm}$ and slippage of the belt is a potential problem. Using steel with reduced diameter wheels then the torque is still in excess of the rated torque:

$$
\begin{aligned}
T_{m} & =\left\{0.249+1.69+2.8^{2}(0.148+0.0275)\right\} \times 10^{-3} \times 1578 \\
& =\{0.249+1.69+1.38\} \times 10^{-3} \times 1578=5.24 \mathrm{Nm}
\end{aligned}
$$

If we use light-weight wheels so that the inertia can be neglected then:

$$
\begin{aligned}
T_{m} & =\left\{0.249+2.8^{2}(0.148)\right\} \times 10^{-3} \times 1578 \\
& =\{0.249+1.16\} \times 10^{-3} \times 1578=2.22 \mathrm{Nm}
\end{aligned}
$$

Therefore the rating of this motor is marginal. A chain drive would add too much inertia so that a belt drive with lightweight pulley wheels, or a lightweight gearing system, is required. In addition, there are friction and windage losses as well as the load of the piston due to the compression and vacuuming of the chamber. The piston itself is quite light. An alternative is to use a crank arrangement although this would cause problems if none-sinusoidal movement is required in order to put wave harmonics into the system. The correct drive is currently being investigated. 


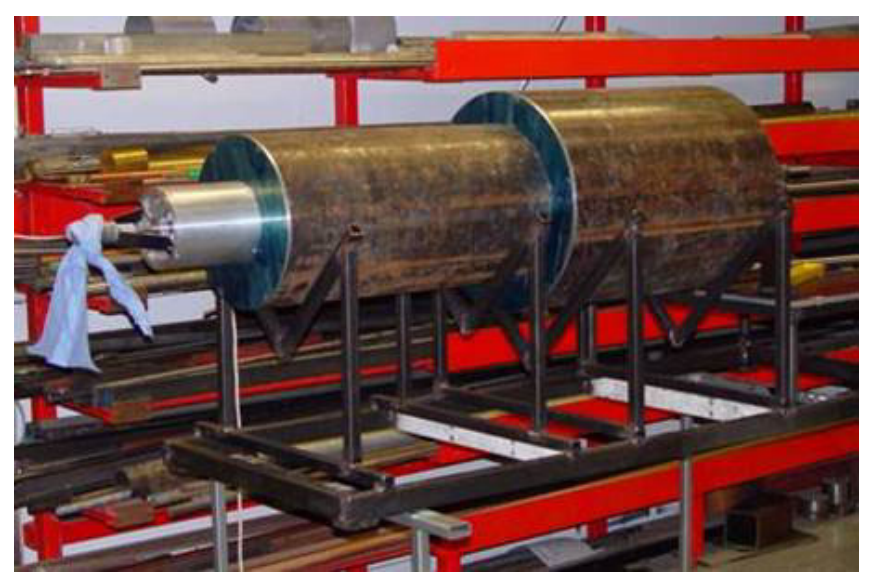

Fig 3 Turbine test bed in manufacture

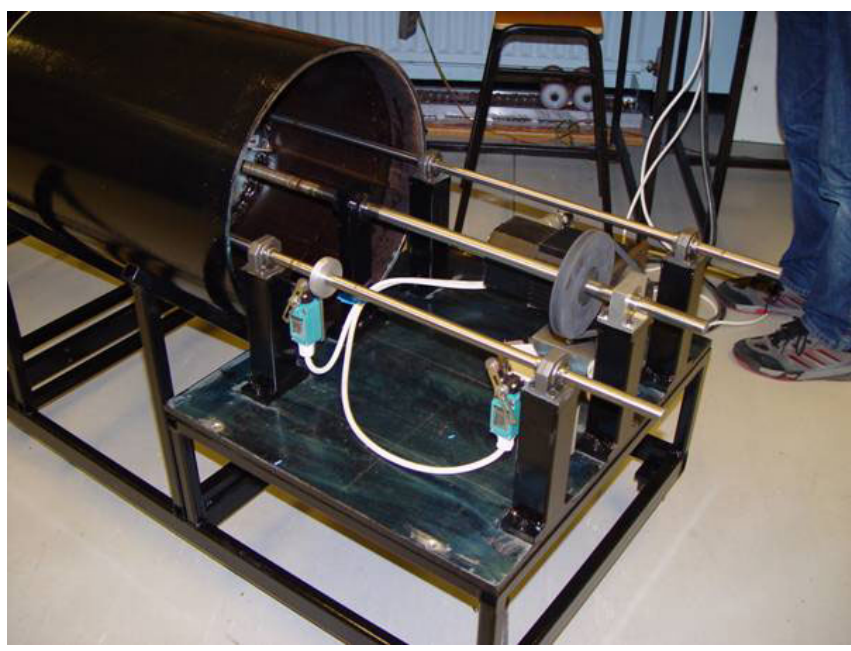

Fig 4 Turbine test bed with first drive fitted

The advantages of this system are that testing of the turbine can be conducted under controlled conditions and the piston fully calibrated and instrumented to measure chamber pressures and even flow rates. The resources required to use this equipment are also minimal.

\section{Flume Wave Generator}

\section{A. Practical arrangement}

A flume in the Department of Civil Engineering of the University of Glasgow has been modified to deliver waves under continuous conditions. The flume is usually used for experimental work into river and tidal flows. However, if a beach is located at the down-stream end and a paddle at the up-stream end then the flume can be used to produce waves with the beach being overtopped so that there is little wave reflection; a diagram is shown in Fig 5 for this arrangement.

Fig 6 shows photographs of the paddle arrangement. This is now totally enclosed due to water splashing and further modification is expected as described below. Fig 8 shows the flume when producing waves. Fig 9 shows a typical project with a student developing a wave measurement system using an array of wave probes.

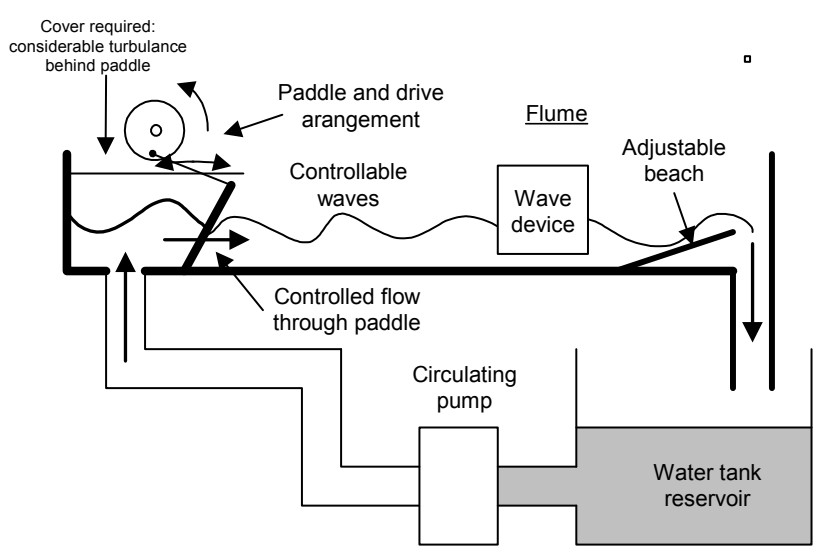

Fig 5 Flume arrangement with paddle

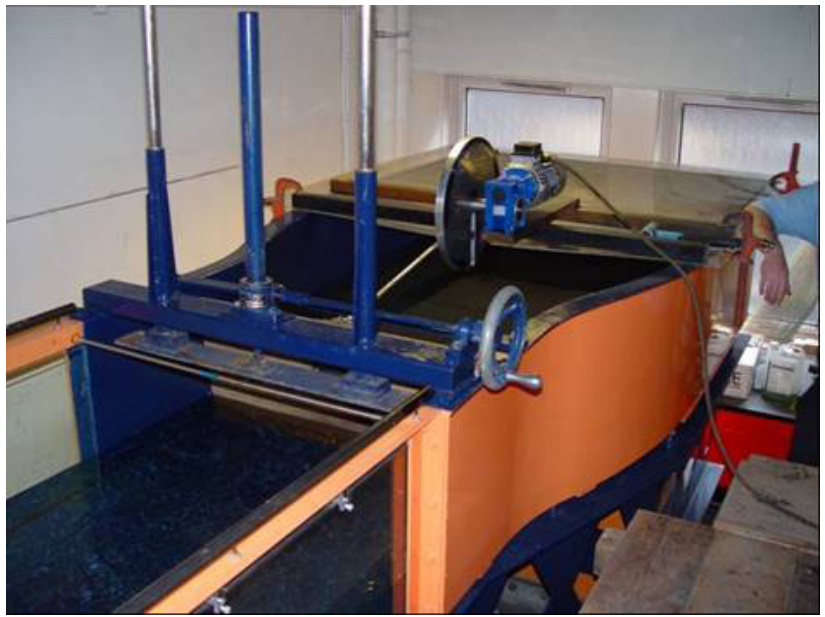

Fig 6 Paddle arrangement of flume

\section{B. Dimensions of flume and paddle arrangement}

The flume is about $10 \mathrm{~m}$ in length with a width of $890 \mathrm{~mm}$ and a depth of about $300 \mathrm{~mm}$ to $400 \mathrm{~mm}$ depending on the height of the beach. A list of dimensions is given in Table I with a key in Fig 7.

Table I

\begin{tabular}{|l|l|l|}
\hline Flume length for paddle to beach & $\mathrm{Lt}$ & $7.2 \mathrm{~m}$ \\
\hline Back tank length & $\mathrm{Bt}$ & $3.2 \mathrm{~m}$ \\
\hline Back tank width (not shown) & & $1.4 \mathrm{~m}$ \\
\hline Fume height & $\mathrm{Ht}$ & $460 \mathrm{~mm}$ \\
\hline Beach height & $\mathrm{Bh}$ & $\begin{array}{l}\text { Adjustable (set to } \\
275 \mathrm{~mm} \text { in tests } \\
\text { below) }\end{array}$ \\
\hline Beach length & $\mathrm{Bl}$ & $350 \mathrm{~mm}$ \\
\hline Paddle height & $\mathrm{Ph}$ & $450 \mathrm{~mm}$ \\
\hline Paddle width (not shown) & & $\begin{array}{l}830 \mathrm{~mm}(30 \mathrm{~mm} \\
\text { gaps either side) }\end{array}$ \\
\hline Flume width (not shown) & & $890 \mathrm{~mm}$ \\
\hline Paddle drive arm & $\mathrm{Pa}$ & $\begin{array}{l}600 \mathrm{~mm} \\
\text { (adjustable) }\end{array}$ \\
\hline Drive wheel axis height & $\mathrm{Wh}$ & $710 \mathrm{~mm}$ \\
\hline $\begin{array}{l}\text { Horizontal distance between drive } \\
\text { wheel axis and paddle hinge }\end{array}$ & $\mathrm{Cl}$ & $510 \mathrm{~mm}$ \\
\hline Drive wheel torque arm length & $\mathrm{Ta}$ & Adjustable \\
\hline
\end{tabular}




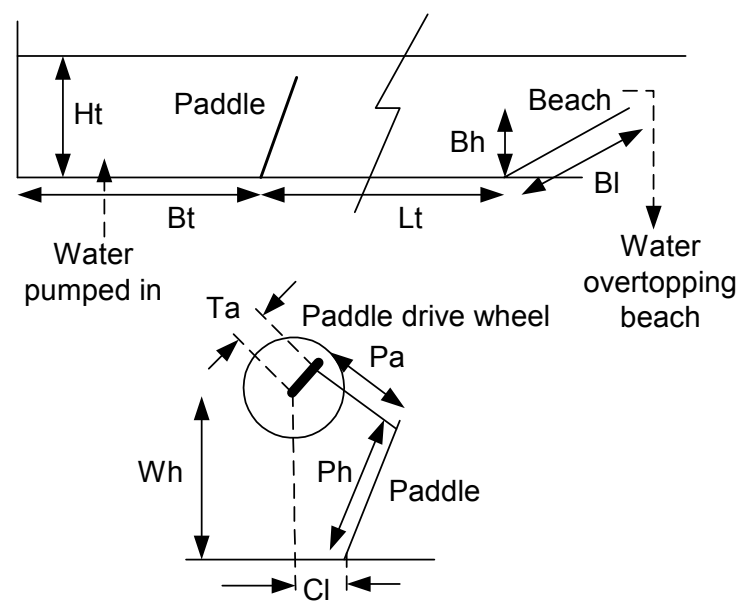

Fig 7 dimension key for Table I

Initially it was envisaged that the circulating pump could be pulsed to produce waves; however under test this was found to be impractical, therefore the paddle method of wave production was developed. The paddle drive wheel is driven by a 2-pole inverter-drive $0.75 \mathrm{~kW}$ induction motor with a step-down gearbox with a ratio of 25 . At full load the speed drop of the motor is about $200 \mathrm{rpm}$ however this would only be at a high drive wheel torque arm radius - in reality this is not normally used and at low torque arm length the motor will run close to the synchronous speed. Therefore the wave frequency will be approximately the inverter frequency divided by 25 .

This experimental rig is cost effective and the types of project that are being applied to include:

- Development of wave probe array systems for use of short-term wave deterministic algorithms

- Small-scale wave generator models

This system is smaller in scale that a wave tank used in marine engineering departments for testing ship hulls etc and requires much less resourcing. The flume is shown working in Fig 8.

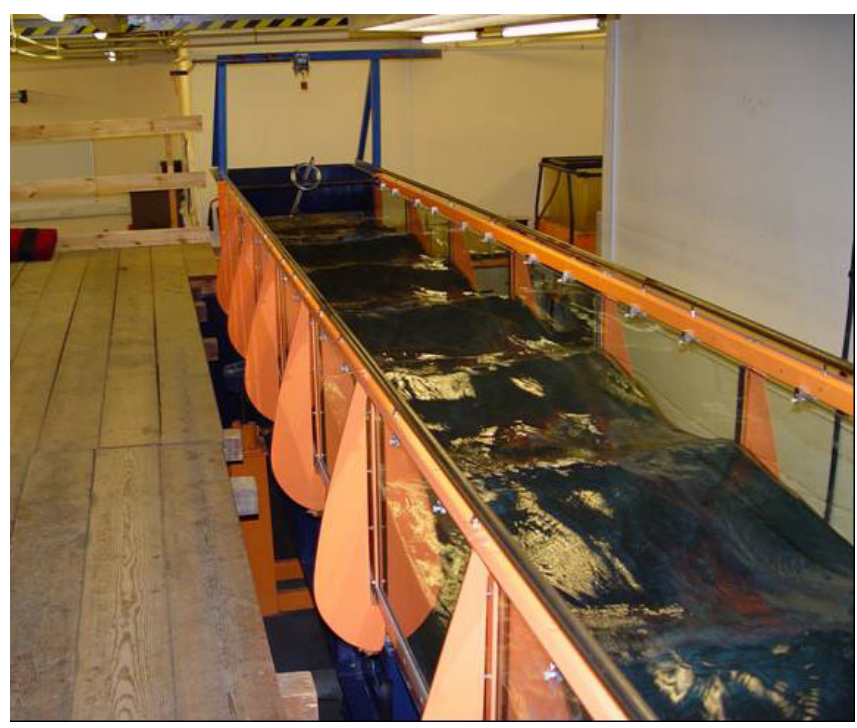

Fig 8 Waves in Flume
One of the first projects run was to develop an array of wave probes to monitor the waves. This can be seen in Fig 9. The first approach used the variation of capacitance between copper probes. This had limited success due to interference in the signal by the inverter drives of the pump and paddle. The second attempt to develop a wave probe measuring system has been more successful. This used the same probes but reassessed the electronics to alleviate the problem with RF interference and also allow better calibration. At the moment two probes are in use and they are interfaced with a PC which utilises LABVIEW to allow signal conditioning and data logging. The initial results from the calibration of the tank are put forward here. This is necessary to assess the operation of the wave tank and to find a good operating range of the system. Also some interesting problems were discovered.

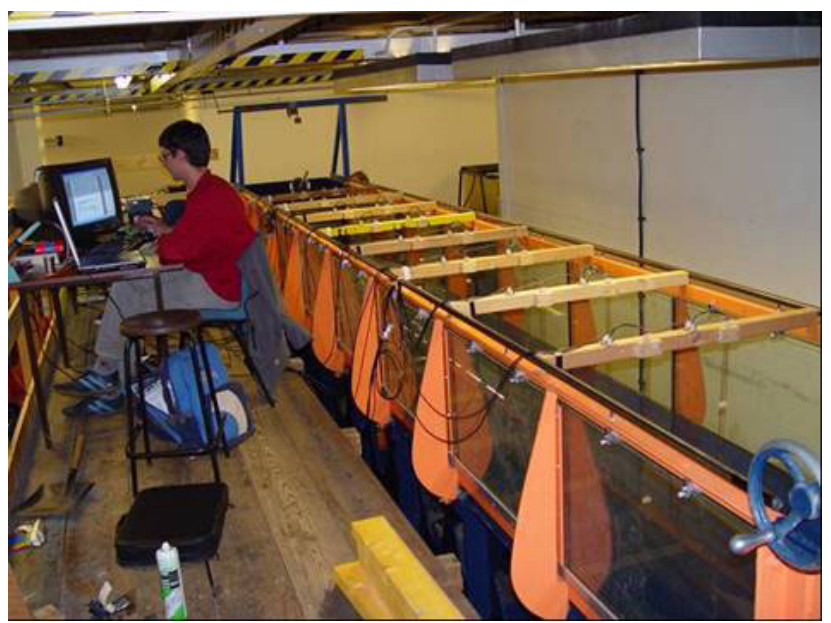

Fig 9 Student developing wave probe arrays

\section{Flume Calibration}

\section{A. Initial settings}

The beach height was set to about $280 \mathrm{~mm}$. With the flume pump running then the flat-calm water height was about 300 $\mathrm{mm}$; the pump is adjusted during wave operation in order to keep the beach top at the level of the wave trough when the waves are overtopping, i.e., the top occasionally breaks the water surface. Two wave probes were used, these both being set one third the way across the flume at $330 \mathrm{~mm}$ from the tank side, One was kept at a constant position from the beach while the other was moved in order to find the wavelengths and also to assess the attenuation of the waves over one wavelength. The reference probe was located 1600 $\mathrm{mm}$ from the front hinge of the beach. It was decided to investigate waves at different drive wheel torque arm setting of $150 \mathrm{~mm}, 100 \mathrm{~mm}$ and $50 \mathrm{~mm}$. It was envisaged that the higher torque arm lengths would be suitable for the low frequency waves while short torque arm lengths would be suitable for the higher frequency waves. This was not found to be necessarily the case.

\section{B. Data acquisition}

The signals from the probes were conditioned and fed into a $\mathrm{PC}$ with the results illustrated using LABVIEW. The signals were digitized with a constant sampling rate. This also allowed the signals to be uploaded in the form of data files 
suitable for use with Microsoft Excel and other packages. The screen display during a capture period is shown in Fig 10. This was the initial screen and it was further modified to gave a display of the difference between the two signals. This was to allow the positioning of the second probe one wavelength ahead of the reference second probe. This was taken at $12 \mathrm{~Hz}$ on the paddle inverter which is a wave frequency of $0.48 \mathrm{~Hz}$. The waveforms were poor due to overtopping of the paddle because of turbulence behind it. This will be discussed later. The $\mathrm{x}$-axis range could be altered to put more waves on the screen and the waveforms on the two screen stored as a set of points in a data file.

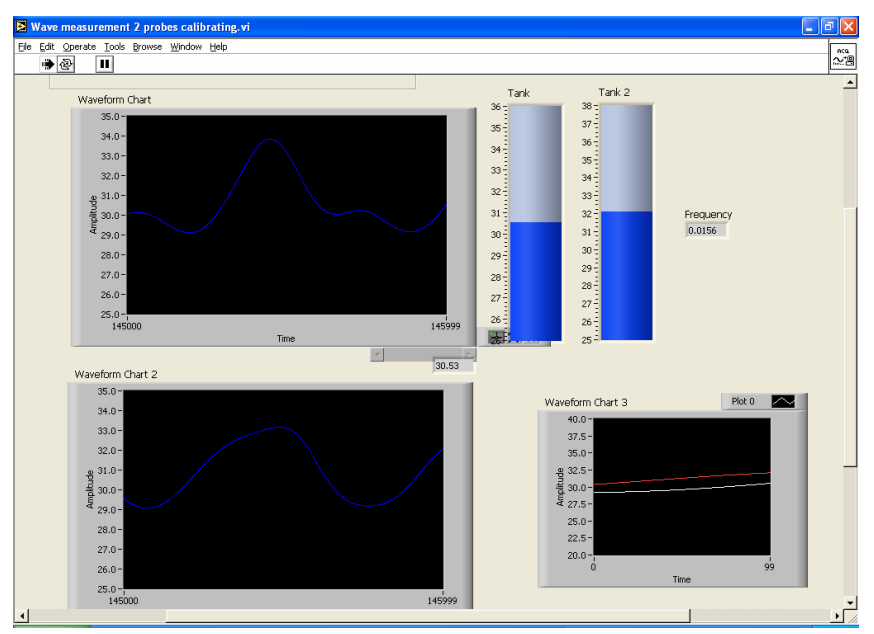

Fig 10 LABVIEW screen

C. Investigation into wavelength and water depth

The flume itself is not very deep and the range of wavelengths available may well fall into the category of "shallow" water, i.e., when the depth is less than a quarter of the wavelength. In deep water the wavelength is given by

$$
L=\frac{g}{2 \pi f^{2}}=\frac{1.56}{f^{2}} \quad \mathrm{~m}
$$

and the velocity is

$$
V=\frac{g}{2 \pi f}=\frac{1.56}{f} \quad \mathrm{~m} / \mathrm{sec}
$$

As the waves get closer to shore the depth becomes shallower and the motion of the waves becomes more elliptical and poorer in quality. In shallow water, if the depth $D$ is less than a quarter of the wavelength $L$ then the velocity is

$$
V=\sqrt{g D}=3.13 \sqrt{D} \quad \mathrm{~m} / \mathrm{sec}
$$

so that the wavelength in shallow water becomes

$$
L=\frac{\sqrt{g D}}{f}=\frac{3.13 \sqrt{D}}{f} \mathrm{~m}
$$

The best results were obtained when the torque arm length was $50 \mathrm{~mm}$, some results were also obtained at $100 \mathrm{~mm}$ (larger waves) but it was found that at $150 \mathrm{~mm}$ the wave quality was low and there was overtopping of the paddle so that only one point was obtained. Fig 11 shows the wavelengths described by equations 8 and 11 for deep and shallow water and the wavelengths of waves measured for a torque arm length of $50 \mathrm{~mm}$. It can be seen that the wavelength initially follows the shallow wavelength but as the frequency increases, and the wavelength shortens, the flume begins to act as a deep water channel. Discrepancies could be due to several reasons, firstly measuring the wavelengths by placement of wave probes one wavelength apart is not easy, especially when the waveforms are not pure sine waves. In addition, the wave frequency is obtained by assuming the paddle drive is operating at the synchronous speed. Obviously further work is needed here to measure the paddle frequency directly.

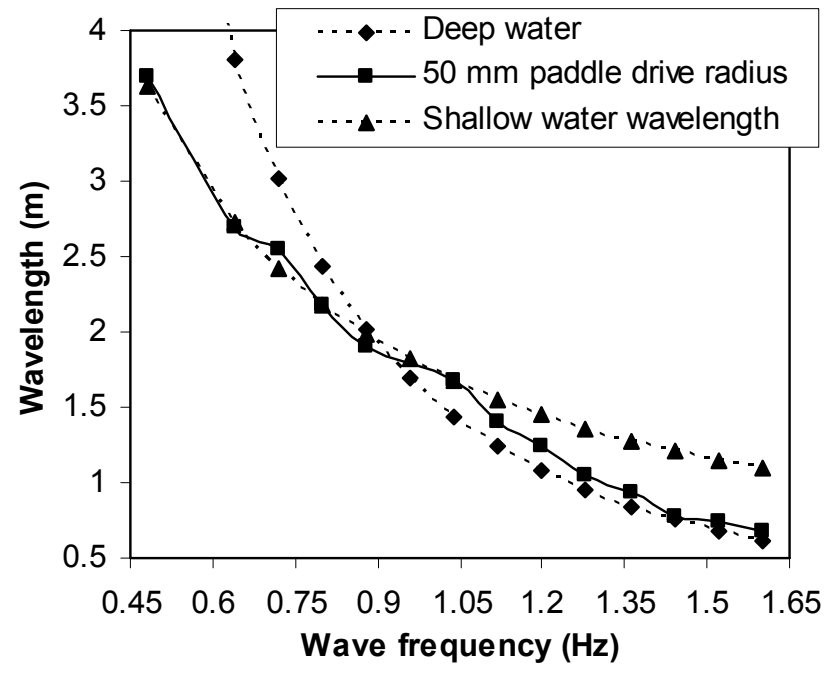

Fig 11 Comparison of measured wavelengths with deep and shallow wavelength predictions

Different wave heights can be obtained by altering the torque arm length. This does make a slight difference as shown in Fig 12 where the $50 \mathrm{~mm}$ and $100 \mathrm{~mm}$ measurements are shown for comparison; however these are small, with the waves tending to shorten in wavelength as the wave height increases.

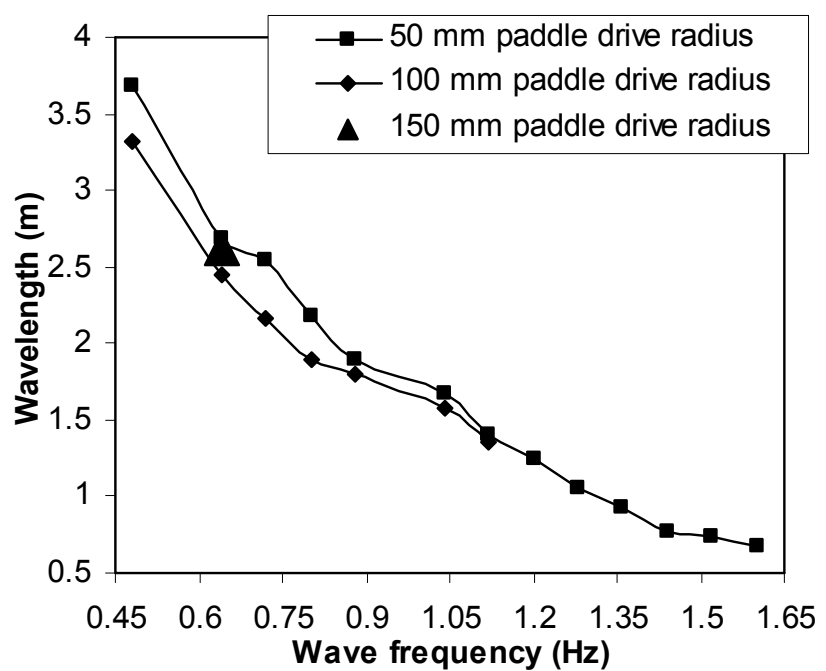

Fig 12 Comparison of wavelengths with different paddle torque arm lengths 
The $100 \mathrm{~mm}$ torque arm length only goes up to $1.12 \mathrm{~Hz}$ because the wave quality was poor above this point and overtopping of the paddle occurred.

An interesting characteristic was when the paddle was operating with an inverter frequency of $12 \mathrm{~Hz}$ or multiples of this $(24$ and $36 \mathrm{~Hz})$. It was found that there was considerable turbulence behind the paddle with overtopping and poor wave quality. This corresponds to $0.48 \mathrm{~Hz}$ which, if Fig 11 and Table I are inspected shows that the back wall of the flume back tank is approximately one wavelength away from the paddle. Therefore a state of resonance occurs. Therefore a beach needs to be fitted to the back wall to reduce reflection of backwards-travelling waves. Initially this was not thought necessary.

Further experiments will include tilting the flume so that it either deepens or becomes progressively shallow and improvements in the beach to lengthen, make shallower and to cover in energy-absorbing material.

\section{Wave height variation}

There is much variation of the wave height with frequency. Fig 13 shows the variation of measured wave height over a period of time. This is for a torque arm length of $50 \mathrm{~mm}$. It would be expected that the waves would possibly stay constant or decrease from probe 1 (the front probe) to probe 2 (reference probe). However this is only true for some of the results - further work has to be done to produce more uniform waves. This includes putting a beach at the back of the paddle back tank and improvements in the beach.

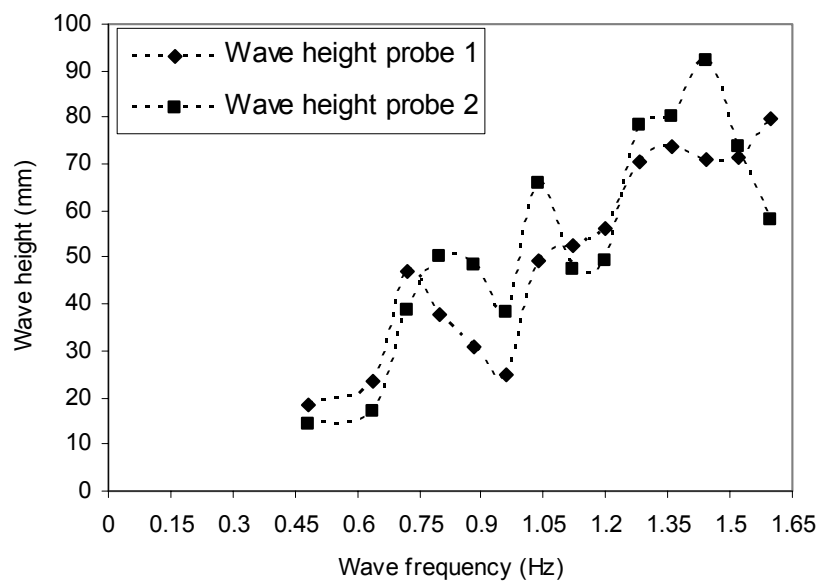

Fig 13 Variation of wave height with $50 \mathrm{~mm}$ torque arm length

If the wave heights are averaged and the power per metre of wave front calculated then the results are shown in Fig 14. Again the variation is large and also there are only a few watts per metre. At the lower frequencies the wave quality is quite good except at wave frequencies of 0.48 and 0.96 $\mathrm{Hz}$. However above about $1.2 \mathrm{~Hz}$ the waves magnitudes begin to pulsate within an envelope - this is shown in the next section.

When the paddle torque arm length was set to $100 \mathrm{~mm}$ then the wave height and power per metre of wavelength are seen in Fig 15; again this shows some inconsistencies although the there was not the pulsating envelope - probably due to the fact the frequency was not increased to the same degree due to overtopping of the paddle. However the power stored in the waves is higher - which is more suitable for use with wave energy generator models.

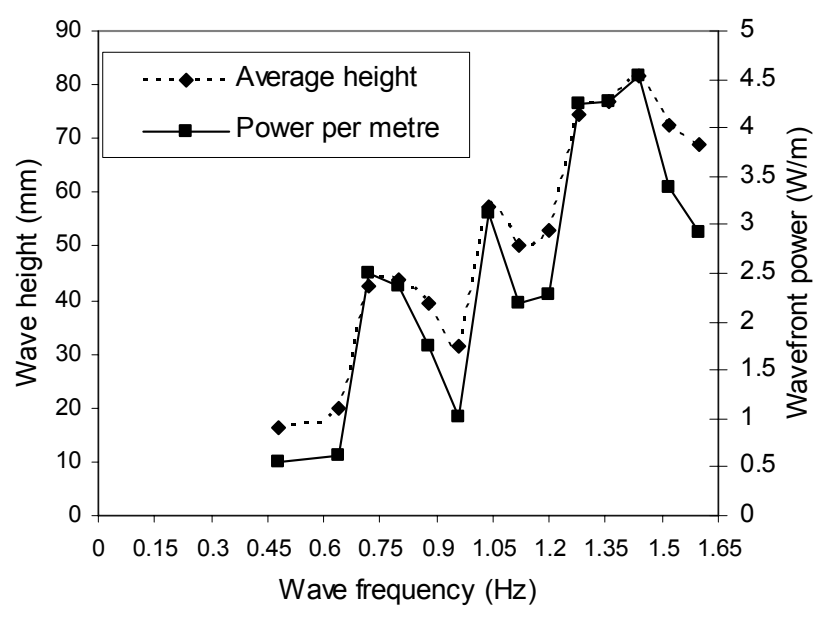

Fig 14 Power per metre of wave front at $50 \mathrm{~mm}$ torque arm

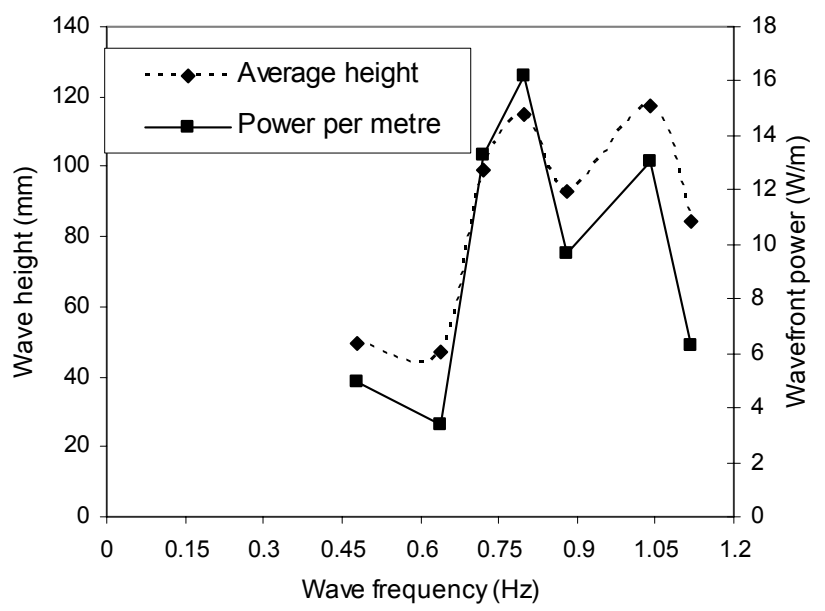

Fig 15 Power per metre of wave front at $100 \mathrm{~mm}$ torque arm

\section{E. Wave quality}

The quality of the waves varied considerably. The waves at resonant frequencies such as 0.48 and $0.96 \mathrm{~Hz}$ were particularly poor. This is illustrated in Fig 16 which compares the waves at 0.48 and $0.64 \mathrm{~Hz}$ for the first (leading) probe.

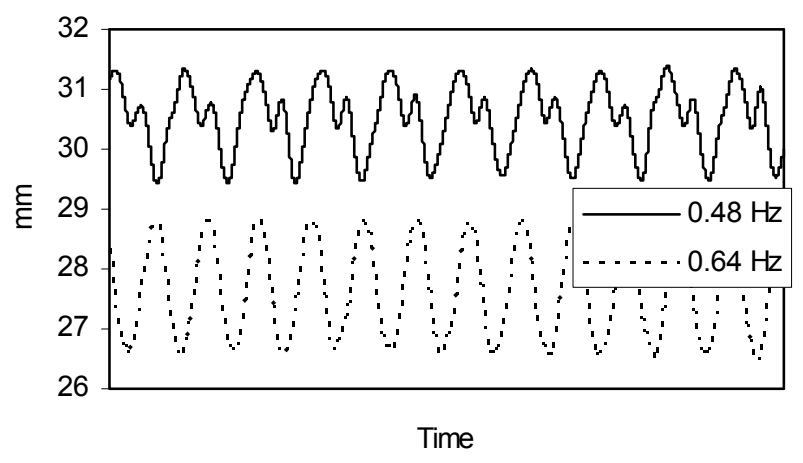

Fig 16 Comparison between 0.48 and $0.64 \mathrm{~Hz}$ waveforms 
At higher frequency and $50 \mathrm{~mm}$ torque arm length then the waves begin to exhibit an envelope. This is illustrated in Fig 17. The waveforms, from top to bottom are for the front probe at frequencies of 1.04, 1.12, 1.28, 1.44 and $1.6 \mathrm{~Hz}$ showing the development of a pulsating envelope. The first two waveforms show a pretty constant magnitude but then a pulsation develops. Obviously this is the initial testing of the wave flume so that it is envisaged there will be further work required to smooth out some operational aspects of the system. For instance, the shape of the paddle and the inclination of it when paddling may make a difference. This could be adjusted using the connecting rod, positioning of the paddle hinges or movement of the torque wheel. Also the beach may be reflecting waves and the flume may need tilting and a back tank beach may make the water flow into the flume smoother.

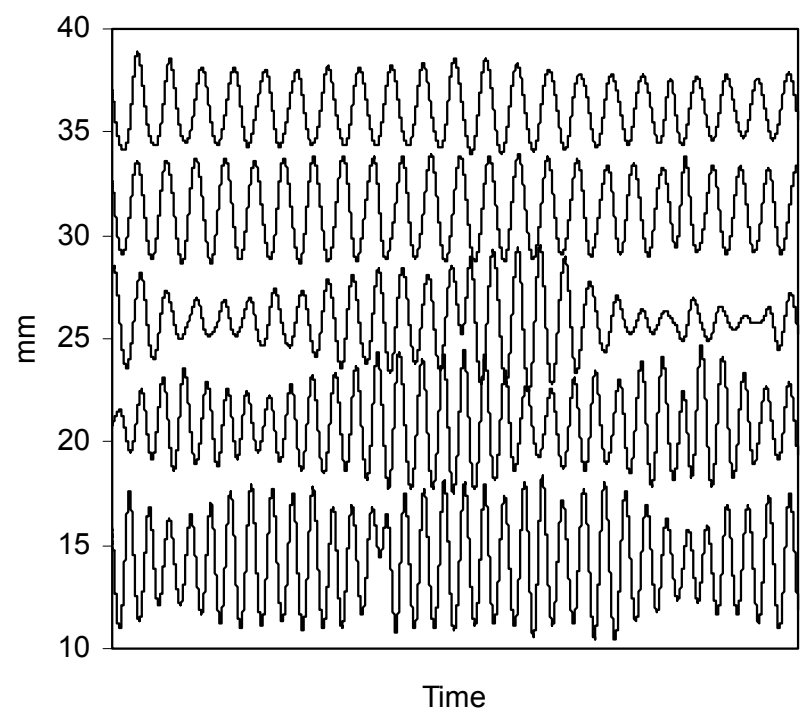

Fig 17 Development of wave envelope with increasing frequency. Wave frequency from top to bottom: 1.04, 1.12, 1.28, 1.44 and $1.6 \mathrm{~Hz}$

\section{Conclusions}

This paper reports on some cost effective solutions to the development of simple systems aimed at investigating energy from sea waves. These can be used for studies ranging from undergraduate projects up to research projects. Further work is to use these systems to develop new models for different aspects of wave generators

\section{References}

[1] D. G. Dorrell, S. Kazi and M. Papadopoulos, "Wave Generator Modelling using an Oscillating Water column and a Wells Turbine" Third IASTED International Conference on Power and Energy Systems 2003, Marbella, Spain, Sept 3-5 2003, pp 69-74.

[2] D. G. Dorrell and M. Findlater, "Computational Fluid Dynamic modelling of a Wells Turbine", IASTED EuroPES conference, Rhodes, Greece, 28-30 June 2004 (on CD).

[3] J. R. Halliday and D. G. Dorrell, "Review of Wave Energy Resource and Wave generator Developments in the UK and the Rest of the World", IASTED EuroPES conference, Rhodes, Greece, 28-30 June 2004 (on CD).

[4] D. G Dorrell, J. R. Halliday, P. Miller and M. Findlater, "Review of Wave Energy Resource and Oscillating water Column Modelling", Universities Power Engineering Conference, Bristol, 5-8 Sept 2004 (on CD). 